\title{
Biomechanical study of the effect of platelet rich plasma on the treatment of medial collateral ligament lesion in rabbits ${ }^{1}$
}

Eduardo Louzada da Costa', Luiz Eduardo Moreira Teixeira", Bruno Jannotti Pádua'", Ivana Duval de Araújo $^{\prime v}$, Leonardo de Souza Vasconcellos ${ }^{\mathrm{v}}$, Luide Scalioni Borges Dias ${ }^{\mathrm{VI}}$

'MSc, Department of Orthopedics, Universidade Federal de Minas Gerais (UFMG), Belo Horizonte-MG, Brazil. Conception and design of the study; acquisition, analysis and interpretation of data; manuscript writing; critical revision.

"PhD, Assistant Professor, Department of Locomotive Apparatus, UFMG, Belo Horizonte-MG, Brazil. Conception and design of the study; acquisition, analysis and interpretation of data; manuscript writing; critical revision.

'"'MD, Department of Orthopedics, UFMG, Belo Horizonte-MG, Brazil. Acquisition, analysis and interpretation of data.

IVPhD, Assistant Professor, Department of Surgery, UFMG, Belo Horizonte-MG, Brazil. Conception and design of the study; acquisition, analysis and interpretation of data; manuscript writing; critical revision.

${ }^{\vee}$ PhD, Assistant Professor, Pharmacy Department, UFMG, Belo Horizonte-MG, Brazil. Acquisition, analysis and interpretation of data; manuscript writing; critical revision.

V'Graduate student, School of Medicine, UFMG, Belo Horizonte-MG, Brazil. Acquisition, analysis and interpretation of data.

\section{Abstract}

Purpose: To evaluate the use of platelet-rich plasma in the early stages of healing of traumatic injury of the medial collateral ligament in the knee of rabbits.

Methods: Thirty rabbits were subjected to surgical lesion of the medial collateral ligament. Of these, 16 were treated with platelet-rich plasma and 14 with saline (control). After 3 and 6 weeks of treatment, $50 \%$ of the animals from each group were sacrificed, and biomechanical tests were performed on the injured ligament to compare the tensile strength between the two groups.

Results: Platelet-rich plasma significantly increased the tensile strength of the ligament in the groups treated after 3 and 6 weeks. In the group treated with platelet-rich plasma vs. saline, the tensile strength values were $3192.5 \pm 189.7 \mathrm{~g} / \mathrm{f}$ vs. $2851.1 \pm 193.1 \mathrm{~g} / \mathrm{f}$ at 3 weeks $(\mathrm{p}=$ $0.005)$ and $5915.6 \pm 832.0 \mathrm{~g} / \mathrm{f}$ vs. $4187.6 \pm 512.9 \mathrm{~g} / \mathrm{f}$ at 6 weeks $(p=0.0001)$.

Conclusion: The use of platelet-rich plasma at the injury site accelerated ligament healing in an animal model, demonstrated by an increase in the tensile strength of the medial collateral ligament.

Key words: Medial Collateral Ligament, Knee. Knee Injuries. Rabbits. 


\section{- Introduction}

Traumatic ligament ruptures are common knee injuries, particularly in young people and during sports practice ${ }^{1}$. The medial collateral ligament $(\mathrm{MCL})$ is the most commonly injured ligament in the knee, and its incidence appears to be higher because incomplete and mild injuries are not often diagnosed ${ }^{2}$. The injuries occur when a valgus load is applied to a flexed knee. Other causes include forced external rotation, anterolateral trauma on the knee, and knee dislocations ${ }^{3}$.Although $\mathrm{MCL}$ injury is the most common, there are controversies regarding the best way to treat it, which includes conservative approaches and surgical procedures ${ }^{4}$.

An alternative to conservative and surgical treatment is a biological stimulus of ligament healing to accelerate the rehabilitation process and avoid the complications of surgical interventions. Among these options, the use of platelet-rich plasma (PRP) can expedite the physiological repair of the ligament ${ }^{5}$. PRP is a platelet concentrate with a platelet count higher than that found in the serum, and its basic mechanism involves the formation of a fibrin mold as a temporary matrix for cell growth and differentiation, helping repair the damaged tissue ${ }^{6}$.

Few studies have evaluated PRP in humans as an adjunct treatment for acute ligament injuries. Experimental studies have suggested that PRP stimulates ligament healing. In addition, PRP increases the synthesis of matrix and collagen, stimulates cell proliferation in the tendon, reduces pain, promotes bone integration, and reduces postoperative complications in MCL lesions and anterior cruciate ligament reconstructions ${ }^{7}$.

We aimed to evaluate the tensile strength of MCL of rabbits treated with plateletrich plasma as compared to a control group.

\section{Methods}

This study was approved by the Animal Research Ethics Committee, UFMG under protocol no354/2013.

We used 30 4-month-old male New Zealand White rabbits weighing 2,475.0 \pm $429.3 \mathrm{~g}$. The animals were kept in individual cages and received water and standard chow (NatureMultivita, SocilGyomarc'H) ad libitum throughout the study period.

The rabbits were randomly distributed into the following experimental groups:

I-control group treated with saline3 weeks after MCL injury $(n=7)$

II-study group treated with PRP 3 weeks after MCL injury ( $n=8)$

III-control group treated with saline 6 weeks after $M C L$ injury $(n=7)$

IV-study group treated with PRP 6 weeks after MCL injury $(n=8)$

\section{MCL injury}

The animals were anesthetized with $100 \mathrm{mg} / \mathrm{kg}$ of ketamine (Ketalar, Sigma, St. Louis, MO, USA) and $8 \mathrm{mg} / \mathrm{kg}$ of xylazine (Rompun, Sigma, St. Louis, MO, USA), and treated with prophylactic antibiotic (cefazolin at $50 \mathrm{mg} / \mathrm{kg}$; Kefazol, ABL, Cosmópolis, São Paulo, Brazil). Afterward, the animals were placed in supine position on the surgical table and trichotomy was performed on the medial side of the knee of the left posterior limb. $\mathrm{MCL}$ was identified by translucency.Then, the surgical site was sterilized, and a longitudinal parapatellar medial incision was performed on the knee. After isolating the superficial MCL and immobilization of the whole limb, a hemostat was positioned under the ligament and a force was exerted in the cephalic direction to rupture the ligament in mop-end lesion in its substance and femoral insertion (Figures 1 and 2$)^{8}$. 


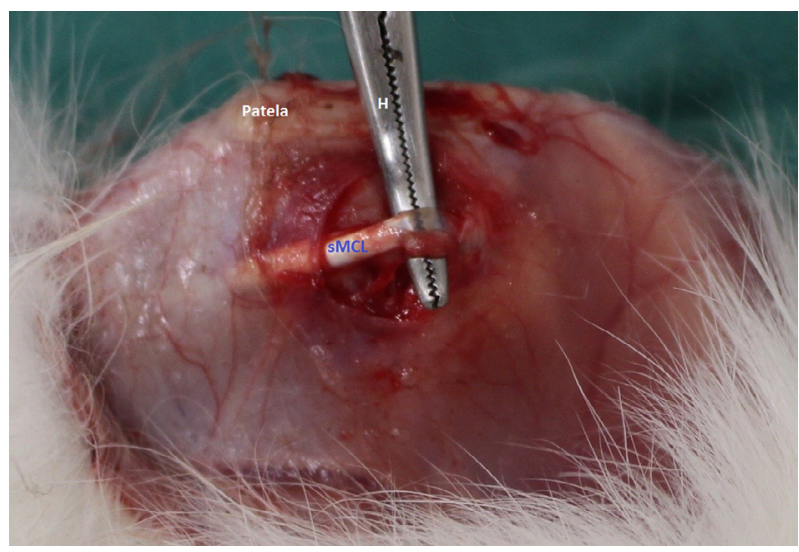

Figure 1 - Hemostat positioned under medial collateral ligament to rupture the ligament in tip swab. Patela: patella bone; $\mathbf{H}$ : hemostat; $\mathbf{s M C L}$ : superficial medial collateral ligament.

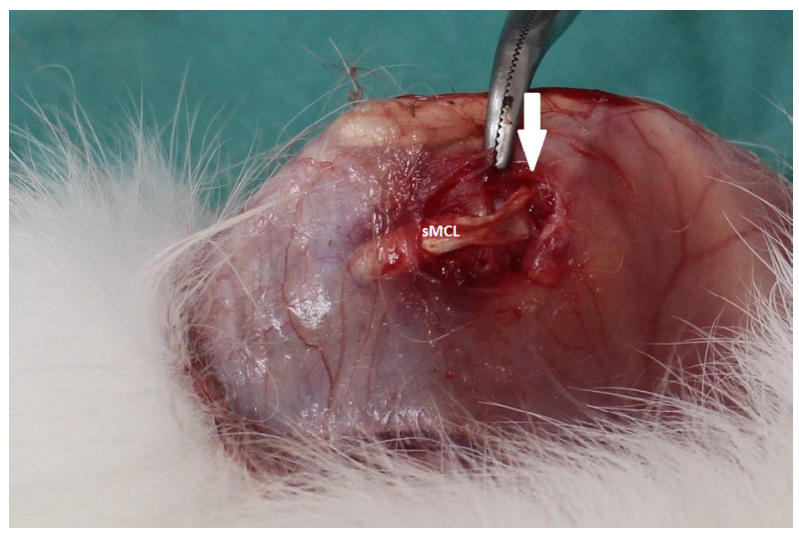

Figure 2 - Lesion in the femoral insertion of medial collateral ligament. SMCL: superficial medial collateral ligament; Arrow: rupture in mop-end lesion.

Subsequently, groups II and IV received $0.2 \mathrm{ml}$ of a PRP infusion at the surgical site in the proximal region of the ligament, and $0.2 \mathrm{~mL}$ was applied via the femoral insertion. Groups I and III received the same volume of saline solution at $0.9 \%$ atthe surgical site to simulate the application performed in groups II and IV. The rupture was closed in a single plane with mononylon4-0 (Ethicon ${ }^{\circ}$ ) 4.0.

\section{PRP preparation}

The protocol used for the preparation of PRP was developed as described by Tavares
Junior ${ }^{9}$. Briefly, blood samples were obtained by punching the central auricular artery, and a 4-mL volume was collected in test tubes containing $0.3 \mathrm{ml}$ of ACD-A-citrate dextrose as the anticoagulant. Immediately after collection, the samples were homogenized and processed using a Cell-DynRuby ${ }^{\circ}$ device (Abbott) for automated platelet quantification ${ }^{2}$.

After calculation of the baseline number of platelets, the samples were centrifuged in a HeraeusMegafuge $11^{\circ}$ centrifuge (ThermoScientific) at a speed of $800 \mathrm{rpm}$ for 8 minutes. The supernatant plasma was transferred to another test tube and subjected to a second centrifugation at a speed of $3200 \mathrm{rpm}$ for $15 \mathrm{~min}$. After the second centrifugation, the upper two-thirds of plasma were discarded, and the platelets present in the lower third of the tube were resuspended. In this step, platelets were quantified in PRP using a final volume between $0.4 \mathrm{ml}$ and 0.5 $\mathrm{ml}$, and PRP was inoculated into each animal.

\section{Evaluation of healing}

Three to 6 weeks after surgery, $50 \%$ of the animals in each group were euthanized with carbon dioxide. The left posterior limbs were disarticulated at the level of the hip joint, and the anatomical specimens were positioned in a linear tensiometer to measure the tensile strength with the knee extended to $0^{\circ}$. Tensile strength was measured for each ligament under constant tension. Data of each animal group were collected blindly by the examiner.

\section{Statistical analysis}

The Kolmogorov-Smirnov test was applied to assess normality in platelet count in the plasma of all animals and PRP in groups II and IV. The same test assessed the normal distribution of the tensile strength in each animal group. The results indicated that the distribution of platelet count and tensile 
strength was normal for all study groups. After the confirmation of these parameters, the results were analyzed using Student's t-test for independent samples and Minitab software version 17,State College, PA at a level of significance of $5 \%$.

\section{- Results}

None of the animals evaluated presented local of systemic signs of infection 3 or 6 weeks after injury.

The platelet count per $\mathrm{mm}^{3}$ in the serum was $325.86 \pm 79.98$ in group I, $311.88 \pm 81.67$ in group II, $331.14 \pm 75.54$ in group III, and $323.87 \pm 66.83$ in group IV, without significant difference between the groups.

The platelet count after centrifugation and preparation of PRP in was $3.32 \pm 0.89$ times the baseline count in group II and 3.33 \pm 0.79 times the baseline count in group IV ( $p$ $=0.48$ ), and the count in PRP was on average 3 times higher than that in the blood, without significant difference between these two groups (Figure 3 ).

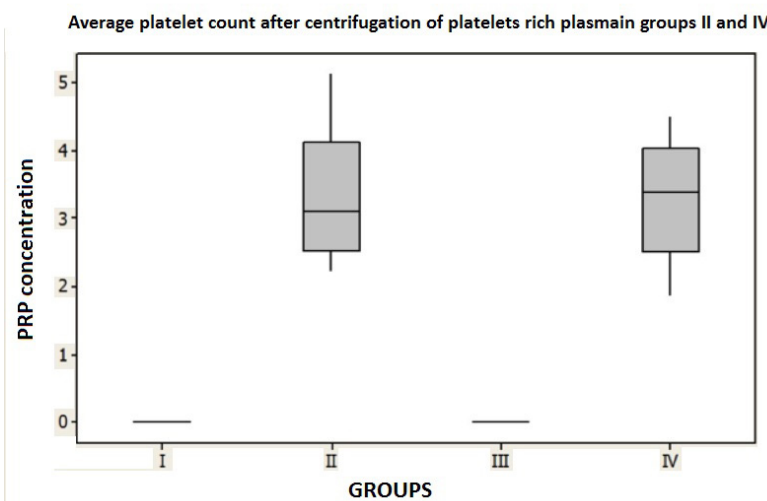

Figure 3-Average platelet count after centrifugation of platelets rich plasma in groups II and IV ( $p=$ N.S.)

There was a non-significant increase in the tensile strength of the ligament in group II $(3.192,5 \pm 189.7 \mathrm{~g} / \mathrm{f})$ and a significant increase in this parameter in group IV $(5.915,6 \pm 832.0$ $\mathrm{g} / \mathrm{f} ; \mathrm{p}=0.00001)$ compared with group I $(2.851,1 \pm 193.1 \mathrm{~g} / \mathrm{f})$ and III $(4.187,6 \pm 512.9$ $\mathrm{g} / \mathrm{f})$.

The comparison between group I $(2.851,1 \pm 193.1 \mathrm{~g} / \mathrm{f})$ and group II $(3.192,5 \pm$ $189.7 \mathrm{~g} / \mathrm{f}$ ) treated3weeks after $\mathrm{MCL}$ injury indicated a significant increase in the tensile strength of the ligament after the use of PRP ( $p=0.005)$. A significant increase was also observed $(p=0.0001)$ in the comparison between group III $(4.187 .6 \pm 512.9 \mathrm{~g} / \mathrm{f})$ and group IV (5.915.6 $\pm 832.0 \mathrm{~g} / \mathrm{f})$ (Figure 4).

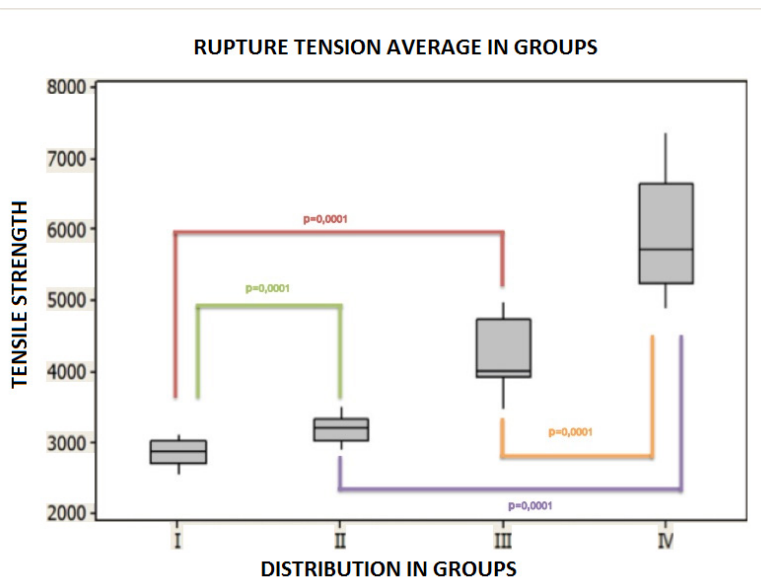

Figure 4 - Tensile strength of the medial collateral ligament $(\mathrm{MCL})$ of rabbits treated with platelets rich plasma (PRP) 3or 6 weeks after MCL injury as an adjunct to healing. I - saline 3 weeks; II - PRP 3 weeks; III - saline 6weeks; IV - PRP 6 weeks; $p=$ N.S.

\section{Discussion}

$\mathrm{MCL}$ is the most commonly injured knee ligament. Smaller lesions heal without intervention; however, full-thickness injuries and insertional lesions heal slowly because of tissue discontinuity ${ }^{10}$.

Several biological and non-biological therapies have been investigated alone or in combination to enhance the healing processand shorten the period of recovery. The 
use of PRP may yield favorable outcomes in the treatment of these injuries owing to its easy of application, low cost, technical availability of production, potential benefits, probable lack of contraindications, and few adverse effects ${ }^{11}$.

Different animal species have been used to study ligament healing. In this study, we chose to use MCL because this ligament is easy to manipulate, has a continuous cross section, may undergo primary healing, treatment options are controversial, and its healing process is reproducible. We chose to use rabbits because their anatomy and physiology of healing are similar to those of humans ${ }^{5,12}$.

We used centrifugation because of its availability and easy handling and because this method yields concentrations similar to those of other methods ${ }^{13,14}$. No platelet activation was performed before the application of PRP because activation can be associated with various intervening factors, including the need to use bovine thrombin, which can cause disseminated intravascular coagulation ${ }^{13}$. Moreover, the previous activation quickly releases the stored growth factors. Once the activation process is triggered, $70 \%$ of the growth factors are released in the first 10 minutes and the remainder within the first hour after application. Harrison et al. ${ }^{14}$ observed that these factors are endogenously activated by type I collagen, and activation occurs continuously over the first five days, allowing the joint release of platelet alpha-granules. The alpha granules are the most studied platelet structures (each platelet has $50-80$ alpha units, and each granule has more than 30 bioactive proteins that can be released by a stimulus). There are different subpopulations of alpha granules, and an early release of these granules by activation with thrombin may promote an exacerbated reaction, leading to the antagonistic action of growth factors, and these factors should be released at different stages of the healing process ${ }^{15}$. In addition, the previous activation can limit the percutaneous application, which is the preferred route used in conservative treatment, owing to the gelation PRP after activation.

The concentrates were prepared individually considering their clinical applicability. PRPwas prepared with the blood of each study animal; this technique is preferably employed in humans, although it is more laborious.Therefore, this procedure will lead to more reliable results in future clinical studies.

In this study, we did not immobilize the knees in the immediate postoperative period, and the analgesic effect and potential acceleration of healing were credited to PRP. Furthermore, Frank et al. ${ }^{16}$ reported that the rabbit knee immobilized for a month was produced less extracellular matrix and collagen type I, resulting in as low recovery that lasted for one year.

The evaluation of biomechanical parameters alone indicated that none of the proposed treatments allowed full recovery of the tensile strength of $\mathrm{MCL}^{17}$.Therefore, PRP could have the potential to re-establish this strength by stimulating the healing process, with the production of extracellular matrix rich in type-I collagen. Therefore, we opted to use the biomechanical tensile strength test alone although we are aware that the disruption of the proximal osteoligamentar junction would limit the performance of histological and immunohistochemical evaluations and prevent the establishment of other inferences, including the likely mechanism associated with the gain of tensile strength in the scar tissue.

This investigation assumed that PRP could improve healing of experimental $\mathrm{MCL}$ lesions in rabbits, and this assumption was corroborated by the results. The comparison of the tensile strength of $M C L$ in all animals after 3 or 6 weeks of injury indicated that PRP was effective in promoting early healing; however, 
the effectiveness was superior after 6 weeks of treatment.

Few studies have evaluated the effect of PRP in ligament or tendon healing, and the studies focused on experimental research with small series. Therefore, there is insufficient data in the literature to allow the formulation of hypotheses to explain the action of PRP in these tissues. For this reason, assumptions need to be made on the basis of data from studies that evaluated other connective tissues, which, despite their specific characteristics, have similar healing processes.

Our results were consistent with those of Yoshioka etal. ${ }^{18}$, who used plasma rich in growth factors to $\mathrm{MCL}$ of rabbits and observed fibroblast proliferation and neovascularization in the scar tissue at the end of the study period. The tensile strength of these ligaments was superior 3 and 6 weeks after treatment. However, the authors used a growth factor concentrate obtained from a single donor. Ueshimaetal. ${ }^{19}$ and Anaguchiet al. ${ }^{20}$ applied growth factors in isolation to $\mathrm{MCL}$ and patellar tendon of rabbits. The first authors observed improvement of histological scores with increased neovascularization and improved the alignment of collagen fibers compared with the control group; however, no significant difference in tensile strength was observed between the groups. The second authors found a significant increase in tensile strength compared with the group treated with saline or the untreated group ${ }^{19,20}$. Other authors also obtained favorable results using PRP in ligament repair. Murray et al. ${ }^{21}$ applied a PRP mold to LCA rupture in dogs and observed significant improvement in biomechanical tests.

Van den Dolderet al. ${ }^{22}$ applied PRPs from humans, rats, and goats to cultures of bone marrow cells from mice and compared the osteogenic response and production of growth factors between these PRPs. They observed that human PRP had a higher concentration of growth factors and stimulated cell proliferation in all cultures. This result may explain why a similar study in rats did not find similar results. Amar et al. ${ }^{23}$ subjected rats to $\mathrm{MCL}$ transection, evaluated the animals 3 weeks after the lesion, and found no significant differences in the tensile strength of the ligaments and tissue maturity scores. However, there was a selection bias in relation to the animal model because the healing process in mice is known to be more efficient than that in other animals, including humans. Moreover, the authors analyzed the data only after 3 weeks of injury. The results of this and other studies indicate that the maximum effect of the application of PRP occurs after 6 weeks.

A possible beneficial effect of PRP is the stimulation of the expression of growth factors such as TGF- $\beta$, PDGF, and IGF, which are essential to the healing process. Growth factors are involved in proliferation, cell differentiation, and tissue morphogenesis of organs during embryogenesis, postnatal period, and adulthood ${ }^{24}$. A traumatic injury is followed by the formation of a platelet-rich hematoma, which releases growth factors and cytokines, which in turn stimulate the healing process $^{25}$. Kajikawa et al. ${ }^{26}$. applied PRP to rat patellar tendon and found an increase in the number of blood cells using labeled proteins.

PRP may promote the proliferation of fibroblasts. PRP stimulates the expression of the COL 1 and COL 3genes and suppresses the genes that negatively affect the structure of the extracellular matrix ${ }^{29}$; this suggests that PRP affects both mature and undifferentiated cells. In addition, it may influence the rate of collagen expression. The increased production of type-III collagen results in the formation of a fibrotic structure that is structurally inferior to that of the original ${ }^{17}$.

PRP stimulates early healing, which promotes the formation of healthier tissues 
and better organization of fibroblasts and collagen. In such models, regression of granulation occurs, indicating an increase in the repair rate. For this reason, it is possible to observe an increase in scar stiffness ${ }^{30}$.

All these factors together improve the clinical response to rehabilitation. Early onset of weight discharge and mobilization are associated with lower rates of fibrosis, improved range of motion, earlier return to activities of daily living, and higher patient satisfaction.

Therefore, our results suggest that the use of PRP as a conservative treatment for $\mathrm{MCL}$ lesions can be beneficial in acute lesions and accelerate the return to activities of daily living, particularly in elite athletes. However, other studies are necessary to corroborate these results.

\section{Conclusion}

The application of platelet-rich plasma to medial collateral ligament lesions in rabbits significantly increased the tensile strength in the groups treated 3 and 6 week safter lesion compared to the control group.

\section{References}

1. Cimino F, Volk BS, Setter D. Anterior cruciate ligament injury: diagnosis, management, and prevention. Am Fam Physician. 2010 Oct 15;82(8):917-22. PMID: 20949884.

2. Ellsasser JC, Reynolds FC, Omohundro JR. The non-operative treatment of collateral ligament injuries of the knee in professional football players. An analysis of seventy-four injuries treated non-operatively and twentyfour injuries treated surgically. J Bone Joint Surg Am. 1974 Sep;56(6):1185-90. PMID: 4436355.

3. Miyamoto RG, Bosco JA, Sherman $\mathrm{OH}$. Treatment of medial collateral ligament injuries. J Am Acad Orthop Surg. 2009 Mar;17(3):152-61. PMID: 19264708.

4. Noyes FR, Barber-Westin SD. The treatment of acute combined ruptures of the anterior cruciate and medial ligaments of the knee. Am J Sports Med. 1995 Aug;23(4):380-9. PMID: 7573644.

5. Andia I, Sanchez M, Maffulli N. Tendon healing and platelet-rich plasma therapies. Expert Opin Biol Ther. 2010 Oct;10(10):141526. PMID: 20718690.

6. Marx RE. Platelet-rich plasma (PRP): what is PRP and what is not PRP? Implant Dent. 2001;10(4):225-8. PMID: 11813662.

7. Pressman $A$, Johnson $D H$. A review of ski injuries resulting in combined injury to the anterior cruciate ligament and medial collateral ligaments. Arthrosc J Arthrosc Relat Surg Off Publ Arthrosc Assoc N Am Int Arthrosc Assoc. 2003 Feb;19(2):194-202. PMID: 12579153.

8. Weiss JA, Woo SL, Ohland KJ, Horibe S, Newton PO. Evaluation of a new injury model to study medial collateral ligament healing: primary repair versus nonoperative treatment. J Orthop Res Off Publ Orthop Res Soc. 1991 Jul;9(4):516-28. PMID: 2045978.

9. Tavares Junior WC. Efeito do plasma rico em plaquetas (PRP) na regeneração do tendão de aquiles em coelhos - avaliação por ressonância magnética e histopatologia [Dissertação]. Universidade Federal de Minas Gerais; 2014 Disponível em: http:// www.bibliotecadigital.ufmg.br/dspace/ handle/1843/BUBD-9ZCPQW?show=full

10. Felson DT, Lawrence RC, Dieppe PA, Hirsch R, Helmick CG, Jordan JM, Kington RS, Lane NE, Nevitt MC, Zhang Y, Sowers M, McAlindon T, Spector TD, Poole AR, Yanovski SZ, Ateshian G, Sharma L, Buckwalter JA, Brandt KD, Fries JF. Osteoarthritis: new insights. Part 1: the disease and its risk factors. Ann Intern Med. 2000 Oct 17;133(8):635-46. PMID: 11033593.

11.Takeyama N, Sakai H, Ohtake H, Mashitori $H$, Tamai K, Saotome K. Effects of hyperbaric oxygen on gene expressions of procollagen, matrix metalloproteinase and tissue inhibitor of metalloproteinase in injured medial collateral ligament and anterior cruciate ligament. Knee Surg Sports Traumatol Arthrosc Off J ESSKA. 2007 Apr;15(4):443-52. PMID: 17187281.

12.Proffen $B L$, McElfresh $M$, Fleming $B C$, Murray MM. A comparative anatomical study of the human knee and six animal 
species. The Knee. 2012 Aug;19(4):493-9. PMID: 21852139.

13.Lozano ML, Pérez-Ceballos $E$, Rivera J, Paunovic D, Candela MJ, Vicente V. Evaluation of a new whole-blood filter that allows preparation of platelet concentrates by platelet-rich plasma methods. Transfusion (Paris). 2003 Dec;43(12):1723-8. PMID: 14641870.

14.Everts PAM, Brown Mahoney C, Hoffmann JJML, Schönberger JPAM, Box HAM, van Zundert A, Knape JTA. Platelet-rich plasma preparation using three devices: implications for platelet activation and platelet growth factor release. Growth Factors Chur Switz. 2006 Sep;24(3):165-71. doi: $10.1080 / 08977190600821327$.

15.Engebretsen L, Steffen K, Alsousou J, Anitua E, Bachl N, Devilee R, Everts P, Hamilton B, Huard J, Jenoure $P$, Kelberine F, Kon E, Maffulli N, Matheson G, MeiDan O, Menetrey J, Philippon M, Randelli $P$, Schamasch $P$, Schwellnus $M$, Vernec $A$, Verall G. IOC consensus paper on the use of platelet-rich plasma in sports medicine. Br J Sports Med. 2010 Dec;44(15):1072-81. PMID: 21106774.

16. Harrison S, Vavken $\mathrm{P}$, Kevy $\mathrm{S}$, Jacobson M, Zurakowski D, Murray MM. Platelet activation by collagen provides sustained release of anabolic cytokines. Am J Sports Med. 2011 Apr;39(4):729-34. PMID: 21398575.

17. Blair P, Flaumenhaft R. Platelet alphagranules: basic biology and clinical correlates. Blood Rev. 2009 Jul;23(4):17789. PMID: 19450911.

18. Frank C, Woo SL, Amiel D, Harwood F, Gomez M, Akeson W. Medial collateral ligament healing. A multidisciplinary assessment in rabbits. Am J Sports Med. 1983 Dec;11(6):379-89. PMID: 6650715.

19. Frank CB, Loitz BJ, Shrive NG. Injury location affects ligament healing. A morphologic and mechanical study of the healing rabbit medial collateral ligament. Acta Orthop Scand. 1995 Oct;66(5):455-62. PMID:7484130.

20.Yoshioka T, Kanamori A, Washio T, Aoto K, Uemura K, Sakane M, Ochiai N. The effects of plasma rich in growth factors (PRGFEndoret) on healing of medial collateral ligament of the knee. Knee Surg Sports
Traumatol Arthrosc Off J ESSKA. 2013 Aug;21(8):1763-9. PMID: 22527414.

21.Murray MM, Spindler KP, Devin C, Snyder BS, Muller J, Takahashi M, Ballard P, Nanney LB, Zurakowski D. Use of a collagen-platelet rich plasma scaffold to stimulate healing of a central defect in the canine ACL. J Orthop Res Off Publ Orthop Res Soc. 2006 Apr;24(4):820-30. PMID: 16555312.

22.Ueshima K, Kitaoka K, Nakase J, Xu Q, Matsumoto K, Tsuchiya $H$. Promotion of rabbit ligament healing by local delivery of hepatocyte growth factor. J Orthop Sci Off J Jpn Orthop Assoc. 2011 Jul;16(4):451-7. PMID: 21611801.

23.Anaguchi $\mathrm{Y}$, Yasuda K, Majima T, Tohyama $H$, Minami A, Hayashi $K$. The effect of transforming growth factor-beta on mechanical properties of the fibrous tissue regenerated in the patellar tendon after resecting the central portion. Clin Biomech Bristol Avon. 2005 Nov;20(9):959-65. PMID: 16055249.

24.van den Dolder J, Mooren R, Vloon APG, Stoelinga PJW, Jansen JA. Platelet-rich plasma: quantification of growth factor levels and the effect on growth and differentiation of rat bone marrow cells. Tissue Eng. 2006 Nov;12(11):3067-73. PMID: 17518622.

25.Amar E, Snir N, Sher O, Brosh T, Khashan M, Salai M, Dolkart O. Platelet-rich plasma did not improve early healing of medial collateral ligament in rats. Arch Orthop Trauma Surg. 2015 Nov;135(11):1571-7. PMID: 26298561.

26.Schilephake $H$. Bone growth factors in maxillofacial skeletal reconstruction. Int J Oral Maxillofac Surg. 2002 Oct;31(5):46984. PMID: 12418561.

27. Martin P, Leibovich SJ. Inflammatory cells during wound repair: the good, the bad and the ugly. Trends Cell Biol. 2005 Nov;15(11):599-607. PMID: 16202600.

28. Kajikawa $Y$, Morihara $T$, Sakamoto $H$, Matsuda K, Oshima Y, Yoshida A, Nagae M, Arai Y, Kawata M, Kubo T. Platelet-rich plasma enhances the initial mobilization of circulation-derived cells for tendon healing. J Cell Physiol. 2008 Jun;215(3):837-45. PMID: 18181148.

29.Schnabel LV, Mohammed HO, Miller BJ, McDermott WG, Jacobson MS, Santangelo $\mathrm{KS}$, Fortier LA. Platelet rich plasma (PRP) 
enhances anabolic gene expression patterns in flexor digitorum superficialis tendons. J Orthop Res Off Publ Orthop Res Soc. 2007 Feb;25(2):230-40. PMID: 17106885.
30.Aspenberg $P$, Virchenko $O$. Platelet concentrate injection improves Achilles tendon repair in rats. Acta Orthop Scand. 2004 Feb;75(1):93-9. PMID: 15022816.

\section{Correspondence:}

Luiz Eduardo Moreira Teixeira

Rua Pio Porto de Menezes, 179/101

30380-300Belo Horizonte - MG Brasil

luizmteixeira@yahoo.com.br

Received: June 23, 2017

Review: Aug 20, 2017

Accepted: Sept 21, 2017
Conflict of interest: none

Financial source: none

${ }^{1}$ Research performed at Laboratory of Experimental Surgery, School of Medicine, Universidade Federal de Minas Gerais (UFMG), Belo Horizonte-MG, Brazil. 